Website: http://journal.umy.ac.id/index.php/mrs

DOI: $10.18196 / \mathrm{jmmr} .5119$.

\title{
Efektifitas Media Video Penggunaan Spill Kit Terhadap Kemampuan Petugas di Rumah Sakit PKU Muhammadiyah Yogyakarta Unit II
}

\author{
Sussy Listiarsasih* \\ *Penulis Korespondensi: sussylistiarsasih@live.com \\ ${ }^{1}$ Rumah Sakit PKU Muhammadiyah Unit II \\ ${ }^{2}$ Magister Manajemen Rumah Sakit Universitas Muhammadiyah Yogyakarta

\begin{tabular}{l}
\hline $\boldsymbol{I} N \boldsymbol{D}$ EXIN G \\
\hline Keywords: \\
Effectiveness of training \\
with video media, spill \\
kit, action research
\end{tabular}

\begin{abstract}
A B S T R A C T
Infection prevention and control programs areinclude to the important programs because the transmission of infection are particularly vulnerable occur in hospitals, especially from body fluid spills. Related to infectious body fluids, spill kit is used to handle it. The use of spill kits are made by the officer who first discovered the infectious body fluids. The study assessed the effectiveness of training with video media on ability of PKU Muhammadiyah Hospital Unit II officers to use spill kit. Qualitative research with action research that consisted of planning, action, observation, and reflection. The training was conducted by video media. The ability of officials assessed by a checklist based on Standard Operating Procedures (SOP) when pretest and posttest. Focus Group Discussion (FGD) also held after the training. The study was conducted during the months of November to December 2015. Data analysis of training value using paired T-Test as support data. There are differences in the ability of PKU Muhammadiyah Hospital officers Unit II in use spill kit before and after training with video media. The SOP that already exist should be revised. There should also be disseminated more adequately on the use of spill kit at PKU Muhammadiyah Hospital Unit II.
\end{abstract}

(C) 2016 JMMR. All rights reserved

Article history: received 12 April 2016; revised 22 Mei 2016; accepted 17 Juni 2016

\section{PENDAHULUAN}

Rumah sakit merupakan sebuah institusi perawatan kesehatan profesional, pusat terapi dan diagnosis yang pelayanannya disediakan oleh dokter, perawat, dan tenaga ahli kesehatan lainnya. Sebagai penyedia pelayanan kesehatan, tentu petugas pelayanan dan staf penunjang seperti petugas laboratorium, peralatan, dan rumah tangga yang bekerja di rumah sakit memiliki resiko tinggi terpapar infeksi yang potensial membahayakan jiwa. Sebanyak $0.3 \%$ petugas kesehatan beresiko terkena infeksi HIV dari darah pasien. Angka kejadian infeksi di RSUP Dr. Sardjito Yogyakarta pada tahun 2005 sebesar 7,95\%. ${ }^{1}$

HAIs merupakan kejadian yang dapat dicegah bukan komplikasi yang tak terduga sebelumnya. ${ }^{2}$ Setiap orang yang bekerja atau orang yang sekadar masuk untuk mengunjungi pasien ke dalam sarana kesehatan memiliki resiko menulari atau tertular suatu infeksi, terutama di rumah sakit yang jenis penyakit dan pelayanan kesehatannya lebih beragam. Universal
Precaution atau kewaspadaan universal adalah tindakan pengendalian infeksi di sarana pelayanan kesehatan yang dilakukan oleh seluruh tenaga kesehatan dan staf lainnya untuk mengurangi resiko penyebaran infeksi dan didasarkan pada prinsip bahwa darah dan cairan tubuh lain dapat berpotensi menularkan penyakit, baik berasal dari pasien maupun petugas kesehatan. ${ }^{3}$

Berkaitan dengan cairan tubuh infeksius, digunakan spill kit untuk menangani tumpahan bahan kimia berbahaya atau cairan tubuh infeksius agar tidak membahayakan orang-orang yang ada di sekitar rumah sakit. Spill kit adalah peralatan yang digunakan untuk membersihkan material yang berbahaya atau infeksius yang berbentuk cair. ${ }^{4}$

Salah satu cara RS PKU Muhammadiyah Unit II untuk membiasakan petugas dalam menggunakan spill kit adalah dengan diberlakukannya SOP atau Standar Operasional Prosedur yang harus di sosialisaskan kepada seluruh petugas hingga akhirnya dapat di aplikasikan di rumah sakit. 
Sosialisasi SOP tersebut dapat diberikan salah satunya dalam bentuk pelatihan penggunaan spill kit bagi petugas. Pelatihan yang diberikan pada petugas diharapkan nantinya dapat menjadi salah satu cara untuk meningkatkan keahlian, pengetahuan, pengalaman, dan perubahan sikap individu berkaitan dengan penggunaan spill kit. ${ }^{5}$

Ada banyak metode pelatihan dengan berbagai media ajar untuk meningkatkan kemampuan seseorang, salah satunya adalah dengan menggunakan video. Selain sebagai media ajar, penggunaan video bisa pula digunakan sebagai sarana sosialisasi penggunaan spill kit kepada petugas lain, karena pada zaman teknologi seperti sekarang ini, sangat mudah sekali berbagi informasi dalam berbagai media termasuk membagikan video antar gadget.

Mengingat pentingnya pencegahan dan pengendalian infeksi di rumah sakit, maka perlu diketahui keadaan yang lebih realistis mengenai fungsi suatu program yang telah dilakukan oleh rumah sakit dalam upaya melaksanakan pelayanan sesuai standar pelayanan minimal berkaitan dengan pencegahan dan pengendalian infeksi. Berdasarkan uraian di atas, penulis tertarik untuk melakukan penelitian tentang Efektivitas Pelatihan Penggunaan Spill kit dengan Media Video Terhadap Kemampuan Petugas (Studi Kasus di RS PKU Muhammadiyah Yogyakarta Unit II).

\section{METODE PENELITIAN}

Jenis dan rancangan penelitian ini adalah kualitatif dengan desain action research, atau penelitian tindakan yang juga merupakan salah satu bentuk rancangan penelitian kualitatif. Action research Adalah proses spiral tiga siklus yang terdiri dari perencanaan, aksi, observasi, dan refleksi. ${ }^{16}$

Tujuan action research ini adalah melakukan perubahan atau intervensi dengan tujuan perbaikan atau partisipasi dalam waktu yang sama. ${ }^{17}$ Action researchsendiri memiliki 2 karakteristik spesifik, yaitu: (a) Proses action research merupakan sebuah siklus yang di dalamnya mencakup kegiatan intervensi, oleh karena itu dinamakan action research. (b) Tingkat keterlibatan subjek dalam penelitian sangat besar, mulai dari pemilihan subjek sebagai informan hingga intervensi.Informan berasal dari populasi petugas RS PKU Muhammadiyah Yogyakarta Unit II.
Teknik pengambilan sampel atau pemilihan informan yang digunakan pada penelitian ini menggunakan teknik purposive sampling, dimana sampel sumber data diambil dengan pertimbangan tertentu. ${ }^{18}$ Pertimbangan tersebut adalah informan harus mewakili dari tiap unit kerja petugas-petugas yang rentan terkena cairan tubuh infeksius.

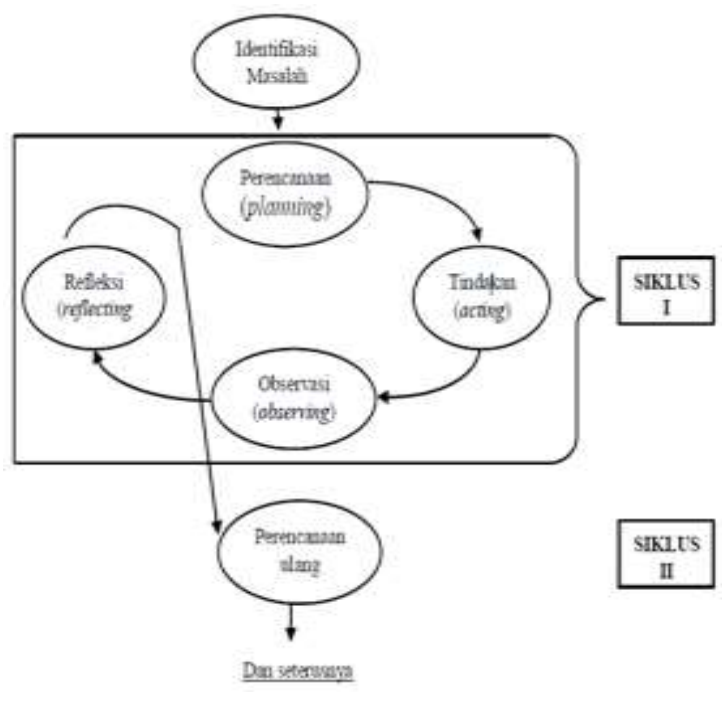

Variabel bebas adalah pelatihan penggunaan spill kit pada cairan tubuh infeksius dengan media video pada petugas RS PKU Muhammadiyah Yogyakarta Unit II. Pelatihan ini dilaksanakan pada masingmasing informan menggunakan media video sebanyak 1 kali setelah dilakukan pretest. Pelatihan penggunaan spill kit adalah suatu tindakan atau proses untuk lebih menguasai cara menggunakan spill kit dengan baik sehingga dapat diterapkan guna meningkatkan penggunaan spill kit terhadap cairan tubuh infeksius.

Pelatihan dilakukan pada kelompok eksperimen dengan menggunakan video setelah sebelumnya dilakukan pretest untuk menilai kemampuan awal peserta. Pelatihan dilaksanakan satu kali yang berdurasi 60 menit. Pretest, pelatihan, dan posttest dilaksanakan pada hari yang sama. Posttest dilaksanakan untuk mengobservasi dan menilai efektivitas pelatihan yang telah diberikan. Variabel tergantung adalah peningkatan kemampuan petugas dalam menerapkan penggunaan spill kit. Peningkatan kemampuan petugas merupakan bertambahnya wawasan dan skill petugas dalam melaksanakan penerapan penggunaan spill kit sehari-hari di RS PKU Muhammadiyah Yogyakarta Unit II. 
Instrument penelitian yang digunakan pada penelitian ini adalah SOP penggunaan spill kit pada cairan tubuh infeksius yang sudah disusun dalam bentuk ceklis atau lembar observasi, panduan Focus Group Discussion (FGD) berupa pertanyaan diskusi, dan panduan wawancara mendalam yang merupakan daftar pertanyaan terbuka yang diajukan oleh peneliti kepada peserta.

Ceklis adalah alat ukur yang digunakan untuk memperoleh data tentang penerapan penggunaan spill kit dalam membersihkan cairan tubuh infeksius yang terdiri dari langkah penggunaan spill kit. Penilaian jawaban di lembar ceklis/observasi tersebut berbentuk tanda check $(\sqrt{ })$, “dilakukan” bernilai 2, "dilakukan tapi tidak sempurna " bernilai 1, "tidak dilakukan" bernilai 0 . Peserta dikatakan mampu menggunakan spill kit dengan baik bila nilai ceklis minimal $\geq 75 \%$ yaitu $\geq 27$ dari total nilai ceklis, yaitu 36. Lembar penilaian uji keterampilan penggunaan spill kit terlampir di akhir halaman. Selain itu, penulis juga menggunakan alat perekam dalam FGD dan wawancara kepada peserta untuk merekam dan mengaji ulang hasil diskusi dan wawancara.

\section{HASIL DAN PEMBAHASAN}

Penelitian dilakukan selama Oktober hingga Desember 2015 proses siklus yang dilakukan terdiri dari planning (perencanaan), action (pelaksanaan), monitoring (observasi), dan reflection (evaluasi).

Informan penelitian tidak hanya terdiri dari petugas kebersihan yang saat ini menjadi petugas yang paling bertanggung jawab bila ada tumpahan infeksius di rumah sakit, tetapi juga perawat di berbagai unit kerja, laboran, dan radiografer yang juga sangat beresiko terpapar cairan tubuh infeksius atau bahan kimia yang berbahaya.

\section{Hasil Analisis Data Kualitatif Siklus I (satu)}

\section{Planning (perencanaan)}

Perencanaan siklus I dimulai dengan mencermati Standard Operating Procedure (SOP) penggunaan spill kit yang sudah tersedia dan di telah disahkan oleh direktur RS PKU Muhammadiyah Yogyakarta Unit II sebagai bahan telaah atau observasi dokumen.
Observasi juga dilakukan pada informan dan peralatan dalam pelaksanaan pelatihan.

\section{Action (pelaksanaan)}

Peneliti mulai mengadakan observasi dan persiapan pelatihan pada bulan Oktober hingga pertengahan November diawali dengan mempelajari SOP penggunaan spill kit.

\section{Monitoring (observasi)}

SOP yang digunakan pada penelitian ini adalah SOP penggunaan spill kit di RS PKU Muhammadiyah Unit II yang telah disahkan oleh direktur RS, tetapi belum terlaksana implementasinya. Rencana uji kelayakan SOP yang pertama dilakukan adalah saat Pelatihan Penggunaan Spill kit dengan Media Video yang diadakan oleh peneliti. Peralatan spill kit sudah tersedia beberapa unit diRuangan Manajemen Mutu untuk tiap unit, tetapi masih belum tersedia lengkap sehingga masih belum bisa dibagikan ke tiap unit kerja.

\section{Reflection (evaluasi)}

SOP yang ada sudah cukup lengkap dan sistematis, maka peneliti dapat membuat ceklis penggunaan spill kit berdasarkan SOP tersebut. Kemudian peneliti pun melengkapi peralatan yang masih kurang. Informan penelitian adalah 20 orang, sehingga total peserta pelatihan dan FGD pun 20 orang yang terdiri dari petugas di berbagai unit kerja.

\section{Hasil Analisis Data Kualitatif Siklus II (dua)}

\section{Planning (perencanaan)}

Penelitian ini diawali dengan perencanaan pelatihan yaitu pembuatan video penggunaan spill kit. Video dibuat dengan bantuan rekan peneliti sebagai tim produksi. Video yang di buat peneliti ada dua buah, yaitu satu video berlatar belakang di IGD yang berdurasi 06:18 menit. Video lainnya berlatar belakang di Instalasi Laboratorium yang berdurasi 06:28 menit. 


\section{Action (pelaksanaan)}

Pelatihan penggunaan spill kit dengan media video dilaksanakan pada tanggal 23 November 2015 di Ruang Meeting 2 RS PKU Muhammadiyah Yogyakarta Unit IIlantai 3 pada pukul 12.30-15.00.

Pada pelatihan ini, peneliti mengundang 1 orang laboran, 1 orang radiografer, 3 orang petugas kebersihan, dan 15 orang perawat sebagai peserta. Total ada 20 orang yang di undang untuk menjadi peserta dalam pelatihan ini, tetapi hanya 19 orang (95\%) yang dapat mengikuti pelatihan secara keseluruhan.

\section{Monitoring (observasi)}

Pengamatan dilakukan oleh peneliti sejak dilakukan pretest, dan pemberian materi pelatihan. Pretest dilakukan dalam 5 pos, penguji adalah rekanrekan peneliti sesama dokter yang telah diberikan pengarahan tentang spill kit dan juga telah melihat video penggunaan spill kit yang telah dibuat oleh peneliti sebelumnya.

Pretest berjalan dengan lancar dan tertib. Setelah semua peserta melakukan pretest dan berkumpul kembali di ruang pelatihan, peneliti memulai pelatihan penggunaan spill kit dengan media video

\section{Reflection (evaluasi)}

Evaluasi dilakukan setelah pemberian materi dengan media video. Pemutaran kedua video spill kit berjalan dengan lancar. Setelah pemutaran video selesai, para peserta dipanggil kembali ke masingmasing pos untuk melaksanakan posttest.

Pada pengamatan di tiap pos, terlihat para peserta pun menjadi lebih mahir dibandingkan pada saat pretest dalam menggunakan spill kit setelah pelatihan. Penilaian pretest dan posttest dilakukan dengan menggunakan lembar ceklis berdasarkan SOP penggunaan spill kit. Berikut tabel 1 menampilkan nilai evaluasi pelatihan penggunaan spill kit saat pretest dan posttest.
Tabel 1. Hasil Penilaian Pretest dan Posttest Peserta Pelatihan Penggunaan Spill kit dengan Media Video

\begin{tabular}{|c|c|c|c|}
\hline \multirow[t]{2}{*}{ No } & \multirow{2}{*}{$\begin{array}{l}\text { Nama } \\
\text { Peserta }\end{array}$} & \multicolumn{2}{|c|}{ Nilai } \\
\hline & & Pretest & Posttest \\
\hline 1. & Peserta 1 & 23 & 36 \\
\hline 2. & Peserta 2 & 22 & 35 \\
\hline 3. & Peserta 3 & 19 & 34 \\
\hline 4. & Peserta 4 & 22 & 35 \\
\hline 5. & Peserta 5 & 21 & 36 \\
\hline 6. & Peserta 6 & 27 & 32 \\
\hline 7. & Peserta 7 & 20 & 34 \\
\hline 8. & Peserta 8 & 15 & 34 \\
\hline 9 & Peserta 9 & 31 & 36 \\
\hline 10. & Peserta 10 & 32 & 33 \\
\hline 11. & Peserta 11 & 29 & 29 \\
\hline 12. & Peserta 12 & 31 & 35 \\
\hline 13. & Peserta 13 & 31 & 36 \\
\hline 14. & Peserta 14 & 21 & 34 \\
\hline 15. & Peserta 15 & 13 & 32 \\
\hline 16. & Peserta 16 & 17 & 36 \\
\hline 17. & Peserta 17 & 28 & 33 \\
\hline 18. & Peserta 18 & 20 & 30 \\
\hline 19. & Peserta 19 & 22 & 35 \\
\hline \multirow{2}{*}{\multicolumn{2}{|c|}{$\begin{array}{c}\text { Total peserta yang } \\
\text { mampu } \\
\text { (nilai } \geq 27 \text { ) }\end{array}$}} & $31.6 \%$ & $100 \%$ \\
\hline & & & \\
\hline
\end{tabular}

Hasil pretest menunjukkan bahwa peserta yang mendapatkan nilai $\geq 27$ adalah 6 orang dan sisanya mendapatkan nilai $\leq 27$, itu berarti peserta yang mampu menggunakan spill kit dengan baik sebelum pelatihan adalah $31.6 \%$. Sedangkan pada posttest, seluruh peserta mendapatkan nilai $\geq 27$, artinya seluruh peserta setelah mengikuti pelatihan mampu menggunakan spill kit dengan baik.

\section{Hasil Analisis Data Kualitatif Siklus III (tiga)}

\section{Planning (perencanaan)}

Peneliti merencanakan untuk mengadakan Focus Group Discussion (FGD). Diskusi dalam bentuk FGD disini dimaksudkan untuk meningkatkan ingatan peserta kembali dengan materi pelatihan yang sebelumnya telah diberikan dan menggali informasi 
lebih dalam terkait penggunaan spill kit di RS PKU Muhammadiyah Yogyakarta Unit II. Keterlibatan peserta dalam diskusi dapat meningkatkan kembali ingatan tentang materi yang telah dipelajari pada pelatihan sebelumnya sebesar $70 \% .{ }^{19}$ Selain itu diharapkan pula akan didapatkan data yang lebih mendalam dibandingkan hanya dengan hasil data yang diperoleh saat pelatihan saja terkait masukan dan saran untuk SOP penggunaan spill kit. FGD diadakan pada hari Sabtu, 5 Desember 2015 pukul 10.30 - 12.00 (90 menit) di Aula RS PKU Muhammadiyah Yogyakarta Unit II lantai 3. Dalam FGD ini, peneliti mengundang seluruh peserta Pelatihan Penggunaan Spill kit dengan Media Video.

\section{Action (pelaksanaan)}

FGD dilaksanakan sesuai dengan rencana semula yaitu pada hari Sabtu, 5 Desember 2015 di tempat yang sudah ditentukan. Undangan yang peneliti kirim sebanyak 19 undangan dan yang dapat menghadiri FGD ini sebanyak 11 orang $(57,9 \%) .8$ orang peserta yang tidak mengikuti FGD diwawancarai oleh peneliti secara pribadi. Penyebab banyaknya peserta yang tidak bisa mengikuti FGD ini adalah waktu FGD yang bertepatan dengan jadwal tugas yang padat, banyaknya pasien dan terbatasnya personil yang bertugas di unit tertentu.

\section{Monitoring (observasi)}

Peneliti sekaligus berperan sebagai moderator untuk mengatur jalannya diskusi dengan mempersilakan kepada peserta FGD untuk membahas pertanyaan diskusi. Berikut ini adalah pertanyaanpertanyaan diskusi FGD. (1) Hal apa yang menyebabkan terjadinya perubahan nilai pretest dan posttest? (2) Apa saja yang harus diperbaiki dari video yang digunakan pada saat pelatihan? (3) Apa saja kirakira hambatan dan kesulitan dalam penggunaan spill kit bila program tersebut sudah diimplementasikan di masing-masing unit kerja? (4) Apakah peralatan spill kit yang ada masih memerlukan dimodifikasi, penambahan, pengurangan, atau penggantian? (5) Apakah ada langkah yang sulit dilakukan dan perlu perbaikan? (6) Pesan dan saran lainnya terkait pelatihan dan rencana implementasi penggunaan spill kit?
Peneliti dibantu oleh 2 asisten peneliti untuk mendokumentasikan jalannya FGD dan menuliskan notulensi hasil diskusi. Peneliti menyimak dan mengawasi diskusi agar berjalan kondusif dan terarah dengan baik.

\section{Reflection (refleksi)}

Setelah dijelaskan ulang tentang spill kit dan langkah-langkah penggunaannya, peserta semakin memahami apa itu spill kit. Pada FGD ini peneliti memberikan beberapa pertanyaan untuk memicu diskusi antar peserta. Masing-masing pertanyaan berhasil membuat peserta memaparkan pendapatnya masing-masing.

Pertanyaan pertama adalah mengenai hal yang menyebabkan terjadinya perubahan nilai pretest dan posttest. Berdasarkan hasil diskusi, didapatkan bahwa jarak pretest dan posttest yang berdekatan membuat peserta mudah untuk mengingat materi, ditambah media ajar pelatihan yang digunakan dalam pelatihan ini adalah video sehingga lebih memudahkan peserta untuk menangkap informasi. Hal ini wajar, karena video merupakan media yang cocok digunakan sebagai media pembelajaran seperti kelas, kelompok kecil maupun secara individual. ${ }^{19}$

Pertanyaan kedua berkenaan tentang saran untuk perbaikan video. Berdasarkan diskusi yang telah dilakukan oleh peserta, masih diperlukan beberapa perbaikan pada video karena video yang digunakan tidak bersuara, tetapi penjelasan tentang langkah penggunaan dipaparkan oleh peneliti. Perbaikan berkisar antara penambahan tulisan atau suara pada video sehingga akan lebih detail, interaktif dan video tetap dapat digunakan untuk mengingat kembali materi walau pelatihan telah selesai.

Pertanyaan ketigaadalah tentang hambatan dan kesulitan dalam penggunaan spill kit bila program tersebut sudah diimplementasikan di masing-masing unit kerja. Sebagian masih belum terbayang hambatan apa yang akan terjadi di tiap unit kerja bila program spill kit ini diimplementasikan. Beberapa peserta khawatir akan kurangnya sumber daya di unit kerja. Bisa jadi tumpahan terjadi pada saat petugas yang berjaga saat itu harus melayani pasien dan akhirnya petugas memanggil CS untuk membersihkan tumpahan. Berkenaan tentang sumber daya, menurut SOP dan teori yang berlaku, pembersihan tumpahan 
harus dilakukan oleh petugas RS yang pertama kali menemukannya. Bisa saja tumpahan darah terjadi saat perawat sedang memasang infus, tetapi jika begitu akan sulit untuk langsung membersihkannya karena kesibukan perawat tersebut dalam melakukan pemasangan infus. Maka kemungkinan perawat tersebut akan membersihkannya tanpa seperangkat spill kit dengan APD seadanya yang sedang ia pakai yaitu hanya handscoen dan masker tanpa apron. Kemungkinan juga perawat lain yang akan membersihkan tumpahan tersebut atau meminta tolong CS untuk membantu membersihkannya.

Pertanyaan keempat kemudian membahas tentang modifikasi peralatan spill kit. Sebagian besar peserta menganggap peralatan spill kit yang ada sudah cukup untuk membersihkan tumpahan di unit kerja. Selain itu peralatan yang ada pun sederhana dan mudah untuk didapat sehingga untuk regulasi dan isi ulang pun akan lebih mudah dilakukan. Ada beberapa peserta yang mengusulkan untuk menambahkan linen tambahan, pembatas menggunakan bahan yang lebih menyerap cairan, dan penambahan klorin cair agar pembersihan tumpahan lebih optimal.

Pertanyaan selanjutnya adalah mengenai modifikasi langkah penggunaan spill kit dan saran untuk implementasi penggunaan spill kit kedepannya. Beberapa peserta mengusulkan untuk memodifikasi langkah pelepasan APD, yaitu handscoen, masker dan apron yang di buka di akhir langkah tanpa harus dimasukkan ke plastik kuning, tetapi tetap dibuang ke tempat sampah medis. Sarung tangan harus segera dipakai bilamana: ${ }^{20}$ (1) Akan terjadi kontak tangan pemeriksa dengan darah, cairan tubuh, selaput lendir, atau kulit yang terluka. (2) Akan melakukan tindakan medik invasif (pemasangan alat-alat vaskular seperti intravena perifer). (3) Akan membersihkan sampah terkontaminasi atau memegang permukaan yang terkontaminasi.

Plastik kuning yang digunakan untuk membuang tumpahan dapat dikategorikansampah terkontaminasiwalaupun petugas sudah berhati-hati dalam membersihkannya agar tumpahan tidak mengenai bagian luar plastik. Maka saran peserta tentang modifikasi langkah dapat dipertimbangkan untuk dilaksanakan, mengingat pentingnya menjaga diri dari benda terkontaminasi. Saran selanjutnya dari peserta untuk program penggunaan spill kit adalah pelatihan yang harus diadakan bagi seluruh petugas di
RS PKU Muhammadiyah Unit II serta meningkatkan sosialisasi dan penambahan alat spill kit di tiap unit.

\section{SIMPULAN}

Persentase peserta pelatihan yang mampu menggunakan spill kit dengan baik dan benar sebelum mengikuti pelatihan penggunaan spill kit di RS PKU Muhammadiyah Unit II adalah 31,6\%. Persentase peserta pelatihan yang mampu menggunakan spill kit dengan baik dan benar setelah mengikuti pelatihan penggunaan spill kit di RS PKU Muhammadiyah Unit II adalah $100 \%$. SOP tentang penggunaan spill kit di RS PKU Muhammadiyah Unit II sudah disusun dengan baik, tetapi masih membutuhkan revisi dalam pelaksanaannya, sehingga dibutuhkan pula revisi dalam redaksinya agar dapat dilaksanakan lebih baik lagi.

Bagian SOP yang membutuhkan revisi adalah mengenai peralatan spill kit, perlu ditambahkan klorin cair dalam botol kecil agar pembersihan tumpahan infeksius lebih bersih dan optimal tanpa harus mencarisumber air bila tumpahan terjadi di tempat yang jauh dari sumber air. Selain itu, rekomendasi revisi lain adalah mengenai langkah penggunaan spill kit, yaitu pelepasan APD (handscoen, masker, dan apron) yang dilakukan diakhir langkah tanpa harus dimasukkan ke plastik kuning, tetapi tetap dibuang ke tempat sampah medis.

Adapun saran dari peneliti adalah

(a) Perlu diadakan pelatihan, simulasi, maupun evaluasi penggunaan spill kit secara berkesinambungan sebagai sosialisasi agar aplikasi dapat lebih maksimal. (b) Penyediaan spill kit di tiap unit kerja harus disediakan lebih dari satu buah. (c) Dibutuhkan evaluasi dalam penugasan pembersihan tumpahan infeksius terkait keterbatasan sumber daya manusia saat jam pelayanan pasien.

\section{DAFTAR PUSTAKA}

1. Marwoto, Agus, 2007, Analisis Kinerja Perawat dalam Pengendalian Infeksi Nosokomial di Ruang IRNA 1 RSUP dr. Sardjito, Yogyakarta.

2. NHMRC, 2010, Clinical Educators Guide for the prevention and control of infection in healthcare. Commonwealth of Australia. Diakses pada 2 Mei 2015 dari 
https://www.nhmrc.gov.au/_files_nhmrc/publicat ions/ attachments/ cd33_icg_clinical_ed_guide.pdf

3. Nursalam \& Kurniawati, N.D. 2007. Asuhan Keperawatan Pasien Terinfeksi HIV/AIDS. Jakarta. Salemba Medika

4. Schaffer, S. Graf (2000). Pencegahan Infeksi dan Praktek yang Aman. Jakarta: EGC

5. Raymond A, Gerhart H, Hollenback J.R, Noe, Wright P.M, 2008. Human Resource Management. McGraw-Hill. New York: McGraw-Hill.

6. Simamora, Henry. 2004. Manajemen Sumber Daya Manusia Edisi III. Jakarta : STIE YKPN.

7. Nawawi, H, 1997. Manajemen Sumber Daya Manusia, Yogyakarta, Universitas Gadjah Mada. Press.

8. Izzudin, M.A. 2013. Efektivitas Penggunaan Media Pembelajaran Video Interaktif Untuk Meningkatkan Hasil Belajar Praktik Servise Engine dan Komponen-Komponennya.Fakultas Teknik Universitas Negeri Semarang. Semarang. 2013. Diakses Pada tanggal 2 Mei 2015 dari http://lib.unnes.ac.id/18840/1/5201409006.pdf

9. Agustriana, Eka. 2014. Efektivitas Penggunaan Video Pembelajaran Untuk Meningkatkan Hasil Belajar Ekonomi Siswa SMA. Pontianak. Program Studi Pendidikan Ekonomi Jurusan Pendidikan Ilmu Pengetahuan Sosial Fakultas Keguruan dan Ilmu Pendidikan Universitas Tanjungpura Pontianak. Diakses pada tanggal 2 Mei 2015 dari http://download.portalgaruda.org/article.php?arti cle $=175049 \& \mathrm{val}=2338 \&$ title $=$ efektivitas $\% 20$ pen ggunaan $\% 20$ video $\% 20$ pembelajaran $\% 20$ untuk $\%$ 20meningkatkan\%20hasil\%20belajar\%20ekono mi\%20siswa\%20sma

10. Nurseto, Tejo. 2011. Membuat Media Pembelajaran yang Menarik. Jurnal Ekonomi dan Pendidikan, Volume 8 No 1, April 2011. Fakultas Ekonomi Universitas Negeri Yogyakarta. Diakses pada tanggal 2 Mei 2015 dari http://journal.uny.ac.id/index.php/jep/article/vie wFile/706/570

11. Sulistyo E.T, dkk. 2011. Media Pendidikan Dan Pembelajaran Di Kelas. Surakarta: UNS Press
12. Breathnach (2005). Nosocomial Infection, Journal Medicine, Volume 33 No3. London. Diakses pada tanggal 2 Mei 2015 dari http://www.sciencedirect.com/science/journal/13 573039/33/3

13. Harmony, B.H .(2007). Nosocomial Bloodstream and intravascular device-related infection. In. Wenzl, R.P. Prevention and Control of Nosocomial Infection.

14. Schaffer, S. Graf (2000). Pencegahan Infeksi dan Praktek yang Aman. Jakarta: EGC

15. Sulaksana,U., 2004, Managemen Perubahan, Cetakan I, Pustaka Pelajar Offset, Yogyakarta.

16. Hasan, 2009. Action Research: Desain Penelitian Integratif untuk Mengatasi Permasalahan Masyarakat, AKSES: Jurnal Ekonomi dan Bisnis, Vol. 4 No. 8, Oktober 2009, Fakultas Ekonomi Universitas Wahid Hasyim. Semarang

17. Utarini, Adi, 2008. Action Research and Triangulation Method in Health Care. disajikan dalam International Workshop on Contemporary Research in Nursing, STIK immanual and Flinders University, Juli : Bandung

18. Supranto. 2000. STATISTIK Teori dan Aplikasi Jilid 1\&2. Penerbit Erlangga. Jakarta.

19. Smaldino, S, Heinich, R., Molenda, M., \& Russell, J. 2008. Instructional media and technologies for learning. New Jersey: Prentice Hall.

20. Departemen Kesehatan RI, 2010, Pedoman Pelaksanaan Kewaspadaan Universal di Pelayanan Kesehatan, Jakarta 